\title{
The Dose of Somatostatin Analogues during Pre-Surgical Treatment Is a Key Factor to Achieve Surgical Remission in Acromegaly
}

\author{
Marta Araujo-Castro ${ }^{1, * \mathbb{D}}$, Eider Pascual-Corrales ${ }^{1}$, Héctor Pian ${ }^{2}$, Ignacio Ruz-Caracuel ${ }^{2} \mathbb{D}$, \\ Alberto Acitores Cancela ${ }^{3}$, Sara García Duque ${ }^{4}$ and Víctor Rodríguez Berrocal ${ }^{3,4}$ \\ 1 Neuroendocrinology Unit, Department of Endocrinology and Nutrition, Hospital Universitario Ramón y \\ Cajal, Instituto de Investigación Biomédica Ramón y Cajal (IRYCIS), 28034 Madrid, Spain; \\ epcorrales@gmail.com \\ 2 Endocrinology Unit, Department of Pathology Hospital Universitario Ramón y Cajal, 28034 Madrid, Spain; \\ hectorpian@yahoo.es (H.P.); iruzcaracuel@gmail.com (I.R.-C.) \\ 3 Neuroendocrinology Unit, Department of Neurosurgery, Hospital Universitario Ramón y Cajal, \\ 28034 Madrid, Spain; alacitores@gmail.com (A.A.C.); vrb09@yahoo.es (V.R.B.) \\ 4 Endoscopic Skull Base Unit, Department of Neurosurgery, Hospital Universitario HM Puerta del Sur, \\ 28938 Madrid, Spain; saragduque83@gmail.com \\ * Correspondence: marta.araujo@salud.madrid.org
}

\section{check for}

updates

Citation: Araujo-Castro, M.; Pascual-Corrales, E.; Pian, H.; Ruz-Caracuel, I.; Acitores Cancela, A.; Duque, S.G.; Berrocal, V.R. The Dose of Somatostatin Analogues during Pre-Surgical Treatment Is a Key Factor to Achieve Surgical Remission in Acromegaly. Endocrines 2021, 2, 241-250. https://doi.org/10.3390/ endocrines 2030023

Academic Editor: Antonio Brunetti

Received: 1 July 2021

Accepted: 3 August 2021

Published: 5 August 2021

Publisher's Note: MDPI stays neutral with regard to jurisdictional claims in published maps and institutional affiliations.

Copyright: (c) 2021 by the authors. Licensee MDPI, Basel, Switzerland. This article is an open access article distributed under the terms and conditions of the Creative Commons Attribution (CC BY) license (https:// creativecommons.org/licenses/by/ $4.0 /)$.
Abstract: Purpose: to determine whether pre-surgical treatment using long-acting somatostatin analogues (SSAs) may improve surgical outcomes in acromegaly. Methods: retrospective study of 48 patients with acromegaly operated by endoscopic transsphenoidal approach and for first time. Surgical remission was evaluated based on the 2010 criteria. Results: most patients, $83.3 \%(n=40)$, harbored macroadenomas and $31.3 \%(n=15)$ invasive pituitary adenomas. In this case, 14 patients were treated with lanreotide LAR and 6 with octreotide LAR, median monthly doses of 97.5 [range 60-120] and 20 [range 20-30] mg, respectively, for at least 3 months preoperatively. Presurgical variables were comparable between pre-treated and untreated patients $(p>0.05)$. Surgical remission was more frequent in those pre-treated with monthly doses $\geq 90 \mathrm{mg}$ of lanreotide or $\geq 30 \mathrm{mg}$ of octreotide than in untreated or pre-treated with lower doses $(\mathrm{OR}=4.64, p=0.025)$. However, no differences were found between pre-treated and untreated patients when lower doses were included or between those treated for longer than 6 months compared to those untreated or pre-treated for shorter than 6 months. Similarly, no differences were found either in terms of surgical or endocrine complications (OR $=0.65, p=0.570)$, independently of the doses and the duration of SSA treatment $(p>0.05)$. Conclusions: the dose of SSAs is a key factor during pre-surgical treatment, since the beneficial effects in surgical remission were observed with monthly doses equal or higher than $90 \mathrm{mg}$ of lanreotide and $30 \mathrm{mg}$ of octreotide, but not with lower doses.

Keywords: acromegaly; somatostatin analogues; presurgical treatment; surgical remission

\section{Introduction}

Acromegaly is associated with a two-fold risk mortality, mainly due to neoplastic disease, but also cardiovascular, respiratory and metabolic complications [1]. However, restoration of normal GH secretion by the different modalities of treatment available improves the prognosis and life expectancy of these patients. At present, transsphenoidal surgery is the first-line therapeutic option in most patients with newly diagnosed acromegaly [2].

However, primary or pre-surgical treatment with somatostatin analogues (SSAs) in patients who are not expected to be cured by surgery could be considered [3,4]. The surgical remission rate is stabilized around $60-75 \%$ in large series from expert centres, but 
the overall remission rates decreased to $40-60 \%$ for macroadenomas and even $10-20 \%$ for invasive macroadenomas [5].

SSAs play an important role in the treatment of GH-secreting pituitary adenomas (PAs) owing to the significant effectiveness in both serum GH reduction and tumour shrinkage [6-8]. However, the question of whether preoperative therapy with SSAs may improve surgical outcome in patients with acromegaly has not been definitively answered [9-11]. Surgical remission and better surgical results have been reported in patients pretreated with SSAs [12,13], although the effect remains inconsistent. Some studies showed that only macroadenoma and invasive macro- or giant PAs benefited from the pre-treatment with SSAs $[14,15]$, whereas others reported advantage in all acromegalic patients [16,17]. On the other hand, some studies showed no apparent beneficial effect of SSAs pre-treatment on surgical outcome [18,19]. Due to the absence of consistent evidence, clinical guidelines for acromegaly recommend SSAs pre-treatment only for selected patients and patients with severe pharyngeal thickness, sleep apnoea syndrome or high-output heart failure [2]. Therefore, the issue of SSAs pre-treatment to improve surgical remission and/or reduce perioperative morbidity is yet to be settled and further studies are necessary to clarify this question. Thus, the aim of our study was to evaluate whether presurgical treatment with SSAs affects surgical outcomes in terms of surgical remission rates and complications in patients with acromegaly. In addition, we analyzed different subgroups of GH secreting-PAs and doses and durations of pre-treatment with SSAs to determine whether there are specific presurgical or pre-treatment features associated with a greater chance of a favourable effect of SSAs.

\section{Materials and Methods}

\subsection{Patients}

Data were collected from a retrospective database of all endonasal endoscopic procedures to pituitary tumours performed at the Hospital Ramón y Cajal and Hospital HM Puerta del Sur between 2008 and 2019. Out of 232 patients with PAs, 56 presented acromegaly. Inclusion criteria were: (i) Confirmed acromegaly diagnosis (GH levels $>1 \mathrm{ng} / \mathrm{mL}$ after oral glucose tolerance test (OGTT) and fasting plasma IGF-1 levels above reference ranges for age and sex [2], (ii) operated by the same neurosurgeon (VRB) and (iii) by endoscopic endonasal transsphenoidal approach. Exclusion criteria were: (i) Previous pituitary surgery and/or radiotherapy, (ii) unavailable information of clinical, hormonal and radiological tumour characteristics in the pre- and postoperative stage and (iii) patients operated by approaches different from transsphenoidal surgery. A total of 48 patients were included in the study (Figure 1).

56 patients with acromegaly who underwent surgery between 2008 and 2019

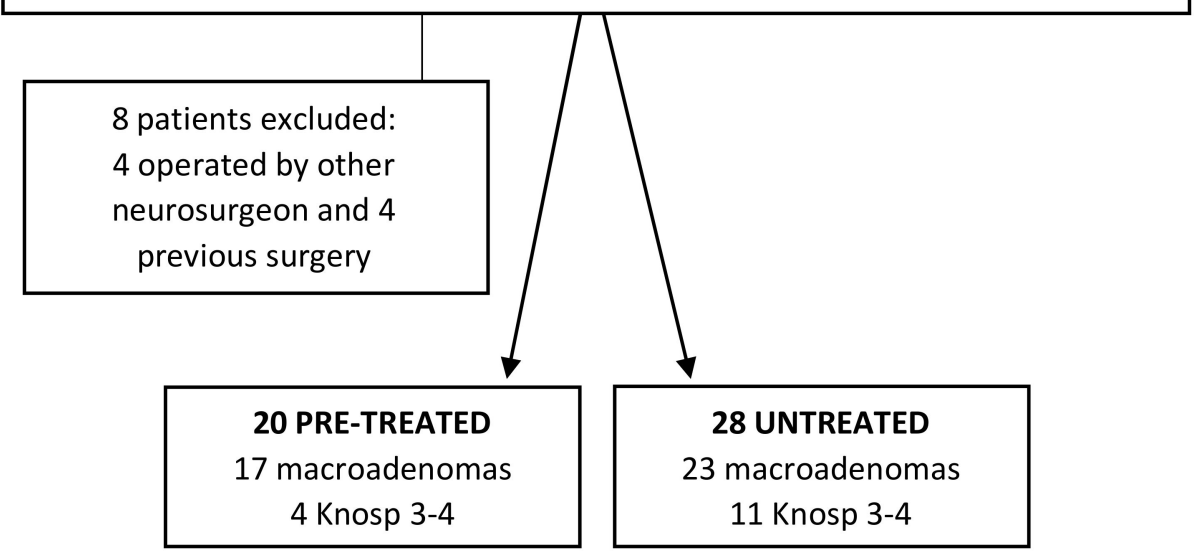

Figure 1. Flowchart of the study design. 
Since near-maximal tumour shrinkage is usually reached within 3 months from the beginning of the therapy, patients in whom the duration of SSAs therapy was less than 3 months were considered as untreated (one patient received only one dose of lanreotide and another two doses of octreotide before surgery). In this case, 20 patients were treated with long-acting SSA in the preoperative stage and the remaining underwent surgery directly. In most cases, the referring endocrinologist decided whether to initiate therapy with SSAs based on tumour size, invasiveness and/or waiting list (Figure 1). Our pituitary tumours register was approved by the local ethical committees of both hospitals (approval date: 4 October 2019, code: ACTA 372).

\subsection{Assays and Remission Criteria}

All anterior pituitary hormones including GH and IGF-1were measured pre- and postoperatively following our protocol [5]. Presurgical measurements were performed at time of diagnosis, before any medical or surgical treatment.

GH and IGF-1 were measured by chemiluminescence assays. Before May 2013 they were measured with IMMULITE 2000 (Siemens Healthineers, Malvern, PA, USA); between May 2013 and October 2018 with Isys (IDS Vitro) and after then, by Liaison XL (Diasorin, Saluggia, Italy). The intraassay coefficient of variation (CV) was $<10 \%$ with all methods. The assays were calibrated according to the WHO international standard for GH and IGF-1 with code $98 / 574$ and $02 / 254$, respectively.

Surgical remission was evaluated at least 3 months after surgery (and at least 4 months in those pre-treated with SSA [20]), using the 2010 criteria (random GH $<1 \mathrm{ng} / \mathrm{mL}$ or GH nadir $<0.4 \mathrm{ng} / \mathrm{mL}$, on OGTT, along with a normal age- and sex-matched IGF-1) [21].

\subsection{Clinical Definitions}

Visual evaluation was performed using our protocol [10], and visual involvement was defined as the presence of any degree of visual acuity compromise, from mild visual acuity involvement to severe and from partial to complete field conditions. For the diagnosis of hypopituitarism, we have employed the same definition as we have previously reported in previous studies [22].

\subsection{Radiological Assessment}

Magnetic resonance imaging (MRI) studies were performed with 1.5T, GE 450w. MRI, sagittal and coronal T1, T2-weighted and dynamic sequences, with gadolinium contrast being performed preoperatively and before any medical or surgical treatment, and 3-6 months postoperatively. Based on the largest diameter of the adenoma, PAs were categorized into microadenoma $(<10 \mathrm{~mm})$, macroadenoma $(\geq 10 \mathrm{~mm})$, very large $(\geq 30 \mathrm{~mm})$ and giant PA ( $\geq 40 \mathrm{~mm}$ ). Tumours were considered invasive into the cavernous sinus when they corresponded to Grade 3 or 4 of the classification of Knosp.

\subsection{Surgical Procedure and Histological Analysis}

Surgeries were performed by an experienced endoscopic pituitary surgeon (VRB) with more than 300 endoscopic pituitary surgeries performed and an average of 35 pituitary surgeries/year during the last 10 years. A conventional endoscopic endonasal approach was used in all surgeries. Tumour consistency was classified in hard tumours when they were difficult to remove with ring curettes and required sharp dissection, bipolar cautery and/or surgical aspirator and the rest were classified as soft tumours [23].

Surgically pituitary tumours were immediately fixed in $10 \%$ buffered formalin and subsequently embedded in paraffin. Standard $\mathrm{H}$ and E-stained sections were used for diagnosis. Immunohistochemical complementary techniques were performed in addition to morphological evaluation to classify specimens based on the 2017 WHO Classification. The following antibodies were used: GH (clone A0570, Dako), cytokeratin (clone CAM5.2, Roche) and Ki67 (clone MIB-1, Dako). 


\subsection{Statistical Analysis}

The statistical analysis was performed with STATA.15. In the descriptive analysis, data were displayed in the form of mean \pm standard error of the mean (SEM) for normal distributed data or median for skewed distributed data, and categorical variables were expressed as absolute and relative (\%) frequencies. Shapiro-Wilk test was used to check the normality assumption; and Levene test to check the variance homogeneity assumption. Differences between continuous parameters was studied with the Student's T tests. For the comparison of categorical variables between independent samples, the chi-squared-test and was performed. Binary logistic regression was employed for analyzing independent predictive variables of surgical remission. Nonparametric receiver-operating characteristic (ROC) curve analysis was used to determine which doses of SSA was the most effective for surgical remission. In all cases, a two-tailed $p$ value $<0.05$ and/or an odds ratio (OR) not including the number one was considered as statistically significant.

A total of 48 acromegalic patients were included in the study, 20 in the pre-treated group and 28 in the untreated group.

\section{Results}

\subsection{Baseline Characteristics}

Patients baseline characteristics are described in Table 1. In this case, 20 patients were treated with SSA in the preoperative stage (Octreotide LAR intramuscular, 6 cases; Lanreotide Autogel subcutaneous, 14 cases) for at least 3 months preoperatively (median, 6.5 months; range, $3-84$ months). In this case, $70 \%(n=14)$ were treated with $\geq 90$ or $\geq 30$ $\mathrm{mg} / \mathrm{month}$ of lanreotide or octreotide, respectively. Median doses were of $97.5 \mathrm{mg} / \mathrm{month}$ (range 60-120) with lanreotide and $20 \mathrm{mg} / \mathrm{month}$ (range 20-30) for octreotide. No differences were found in baseline characteristics between patients pre-treated with SSAs and untreated, but at diagnosis, headache and visual involvement were more common in untreated than in pre-treated patients (Table 1).

Table 1. Baseline characteristics of patients pre-treated with somatostatin analogues and untreated.

\begin{tabular}{cccc}
\hline Variable & Untreated $(n=28)$ & Pre-Treated $(n=20)$ & $p$ Value * \\
\hline Age (years) & $49.6 \pm 2.3$ & $52.2 \pm 3.2$ & 0.511 \\
\hline Female sex & $64.3 \%(n=18)$ & $70 \%(n=14)$ & 0.679 \\
\hline Diabetes & $10.7 \%(n=3)$ & $30.0 \%(n=6)$ & 0.091 \\
\hline Hypertension & $35.7 \%(n=10)$ & $45.0 \%(n=9)$ & 0.517 \\
\hline Heart disease & $10.7 \%(n=3)$ & $5.0 \%(n=1)$ & 0.480 \\
\hline Obesity & $14.3 \%(n=4)$ & $10.0 \%(n=2)$ & 0.658 \\
\hline Sleep apnoea syndrome & $21.4 \%(n=6)$ & $25.0 \%(n=5)$ & 0.772 \\
\hline Pituitary apoplexy & $3.6 \%(n=1)$ & $0.0 \%(n=0)$ & 0.333 \\
\hline Visual involvement & $17.9 \%(n=5)$ & $0.0 \%(n=0)$ & 0.046 \\
\hline Headache & $32.1 \%(n=9)$ & $5.0 \%(n=1)$ & 0.022 \\
\hline Hypopituitarism & $21.4 \%(n=6)$ & $15.0 \%(n=3)$ & 0.574 \\
\hline Presurgical GH $(\mathrm{ng} / \mathrm{mL})$ & $12.3 \pm 3.1$ & $10.5 \pm 1.9$ & 0.664 \\
\hline Presurgical IGF1 $(\mathrm{ng} / \mathrm{mL})$ & $653.2 \pm 58.0$ & $686.5 \pm 67.7$ & 0.711 \\
\hline Macroadenoma & $82.1 \%(n=23)$ & $85.0 \%(n=17)$ & 0.793 \\
\hline Tumour size $(\mathrm{mm})$ & $16.1 \pm 1.7$ & $14.3 \pm 1.7$ & 0.451 \\
\hline Knosp grade 3-4 & $39.3 \%(n=11)$ & $20.0 \%(n=4)$ & 0.098 \\
\hline
\end{tabular}

Presurgical GH and IGF1 levels refers to their values before somatostatin analogues treatment initiation. ${ }^{*} p$ Value refers to the differences between pre-treated and untreated patients. 


\subsection{Surgical Remission (2010 Criteria)}

Surgical cure was achieved in $54.2 \%(n=26)$ of patients, $87.5 \%(n=7)$ in microadenomas, $47.5 \%(n=19)$ in macroadenomas and $13.3 \%(n=2)$ in PA grade Knosp 3-4. We found that surgical remission was more than four times higher in patients treated with high SSAs doses ( $\geq 90 \mathrm{mg} /$ month of lanreotide or $\geq 30 \mathrm{mg} / \mathrm{month}$ of octreotide) compared with those treated with lower doses or untreated (Table 2). Based on the ROC, the dose of $26.3 \mathrm{mg} / \mathrm{months}$ of octreotide (AUC $=1.00$, sensitivity and specificity of $100 \%$ ) and of $90 \mathrm{mg} / \mathrm{month}$ of lanreotide (AUC $=0.66$, sensitivity $75.0 \%$ and specificity of $60.0 \%$ ) were the most effective to achieve surgical remission (Table 2).

Table 2. Surgical remission in patients with acromegaly pre-treated with somatostatin analogues and untreated, according to the type of somatostatin analogue and its dose and duration.

\begin{tabular}{|c|c|c|c|c|}
\hline \multirow{2}{*}{ Patients } & \multicolumn{4}{|c|}{2010 Criteria } \\
\hline & Pretreated & Untreated & $\mathbf{P}$ & Odds Ratio, 95\% CI \\
\hline All patients $(n=48)$ & $60.0 \%(n=12)$ & $50.0 \%(n=14)$ & 0.493 & $\mathrm{OR}=1.50$ [0.47-4.79] \\
\hline Microadenomas $(n=8)$ & $100 \%(n=3)$ & $80 \%(n=4)$ & 0.408 & NC \\
\hline Macroadenomas $(n=40)$ & $52.9 \%(n=9)$ & $43.5 \%(n=10)$ & 0.554 & $\mathrm{OR}=1.46[0.41-5.15]$ \\
\hline $\begin{array}{c}\text { Knosp 2-3 pituitary adenomas } \\
\qquad(n=16)\end{array}$ & $0.0 \%(n=0)$ & $18.2 \%(n=2)$ & 0.360 & $\mathrm{NC}$ \\
\hline $\begin{array}{l}\text { All patients considering high } \\
\text { SSAs dose }(n=48)\end{array}$ & $78.6 \%(n=11 / 14)$ & $44.1 \%(n=15 / 34)$ & 0.029 & $\mathrm{OR}=4.64$ [1.09-19.7] \\
\hline $\begin{array}{l}\text { Macroadenomas considering } \\
\text { high SSAs dose }(n=40)\end{array}$ & $72.7 \%(n=8 / 11)$ & $37.9 \%(n=11 / 29)$ & 0.049 & $\mathrm{OR}=4.39$ [0.95-20.03] \\
\hline $\begin{array}{l}\text { All patients considering } \\
\text { treatment } \geq 6 \text { months with } \\
\text { SSA }(n=48)\end{array}$ & $63.6 \%(n=7 / 11)$ & $51.4 \%(n=19 / 37)$ & 0.473 & $\mathrm{OR}=1.66[0.41-6.64]$ \\
\hline $\begin{array}{l}\text { Macroadenomas considering } \\
\text { treatment } \geq 6 \text { months with } \\
\text { SSA }(n=40)\end{array}$ & $55.6 \%(n=5 / 9)$ & $45.2 \%(n=14 / 31)$ & 0.583 & $\mathrm{OR}=1.52[0.34-6.76]$ \\
\hline $\begin{array}{l}\text { All patients considering } \\
\text { treatment with lanreotide } \\
\qquad(n=48)\end{array}$ & $71.4 \%(n=10 / 14)$ & $47.1 \%(n=16 / 34)$ & 0.124 & $\mathrm{OR}=0.38[0.06-2.28]$ \\
\hline $\begin{array}{l}\text { Macroadenomas considering } \\
\text { treatment with lanreotide } \\
\qquad(n=40)\end{array}$ & $63.6 \%(n=7 / 11)$ & $41.4 \%(n=12 / 29)$ & 0.208 & $\mathrm{OR}=0.5[0.08-3.10]$ \\
\hline $\begin{array}{l}\text { All patients considering } \\
\text { treatment with octreotide } \\
\qquad(n=48)\end{array}$ & $33.3 \%(n=2 / 6)$ & $57.1 \%(n=24 / 42)$ & 0.274 & $\mathrm{OR}=2.81[0.74-10.75]$ \\
\hline $\begin{array}{l}\text { Macroadenomas considering } \\
\text { treatment with octreotide } \\
\qquad(n=40)\end{array}$ & $33.3 \%(n=2 / 6)$ & $50.0 \%(n=17 / 34)$ & 0.451 & $\mathrm{OR}=2.48[0.59-10.40]$ \\
\hline
\end{tabular}

SSAs = somatostatin analogues; Odds ratios make reference to pre-treated versus untreated.

\subsection{Surgical and Endocrine Complications and Tumour Consistency}

No operative or perioperative deaths occurred. Surgical morbidity was recorded in 9 patients and was similar in pre-treated and untreated, independently of the doses or the duration of SSA pre-treatment. Neither difference in the risk of postoperative anterior pituitary dysfunction were observed between pre-treated and untreated patients (Table 3). 
Table 3. Surgical and endocrine morbidity in pre-treated with somatostatin analogues and untreated.

\begin{tabular}{|c|c|c|c|}
\hline Variable & Pre-Treated $(n=20)$ & Untreated $(n=28)$ & $p$ Value \\
\hline Surgical complications & $15.0 \%(n=3)$ & $21.4 \%(n=6)$ & 0.574 \\
\hline New APD & $38.9 \%(n=7)$ & $42.9 \%(n=9)$ & 0.802 \\
\hline Diabetes insipidus * & $15.0 \%(n=3)$ & $21.4 \%(n=6)$ & 0.574 \\
\hline Hospitalization length stay & $6.7 \pm 2.0$ & $6.9 \pm 1.4$ & 0.937 \\
\hline Hard tumours & $15.0 \%(n=3)$ & $28.6 \%(n=8)$ & 0.270 \\
\hline Variable & Pre-treated with High Doses $(n=14)$ & Untreated or low doses $(n=34)$ & $p$ Value \\
\hline Surgical complications & $14.3 \%(n=2)$ & $20.6 \%(n=7)$ & 0.611 \\
\hline New APD & $25.0 \%(n=3)$ & $48.2 \%(n=13)$ & 0.175 \\
\hline Diabetes insipidus & $21.4 \%(n=3)$ & $17.7 \%(n=6)$ & 0.760 \\
\hline Hospitalization length stay & $7.46 \pm 10.6$ & $6.5 \pm 6.20$ & 0.711 \\
\hline Hard tumours & $7.1 \%(n=1)$ & $29.4 \%(n=10)$ & 0.095 \\
\hline Variable & Pre-treated $>6$ Months & $\begin{array}{c}\text { Untreated or Pre-treated }<6 \\
\text { Months }\end{array}$ & $p$ Value \\
\hline Surgical complications & $18.2 \%(n=2)$ & $18.9 \%(n=7)$ & 0.956 \\
\hline New APD & $33.3 \%(n=3)$ & $43.3 \%(n=13)$ & 0.593 \\
\hline Diabetes insipidus & $18.2 \%(n=2)$ & $18.9 \%(n=7)$ & 0.956 \\
\hline Hospitalization length stay & $7.0 \pm 10.99$ & $6.72 \pm 6.38$ & 0.918 \\
\hline Hard tumours & $18.2 \%(n=2)$ & $24.3 \%(n=9)$ & 0.670 \\
\hline
\end{tabular}

$\mathrm{APD}=$ anterior pituitary deficit; NC $=$ not calculable * Diabetes insipidus refers to transient diabetes insipidus (no cases of permanent diabetes insipidus were reported).

The proportion of patients with hard tumours between pre-treated and untreated patients was similar, even when long duration of treatment was considered. However, the proportion of hard tumours decreased in pre-treated patients when high doses were considered (Table 3). Tumours of soft consistency were significantly more common in Knosp 0-2 PAs (87.9\% vs. 53.3\%, $p=0.008)$ (Table 3 and Figure 2).

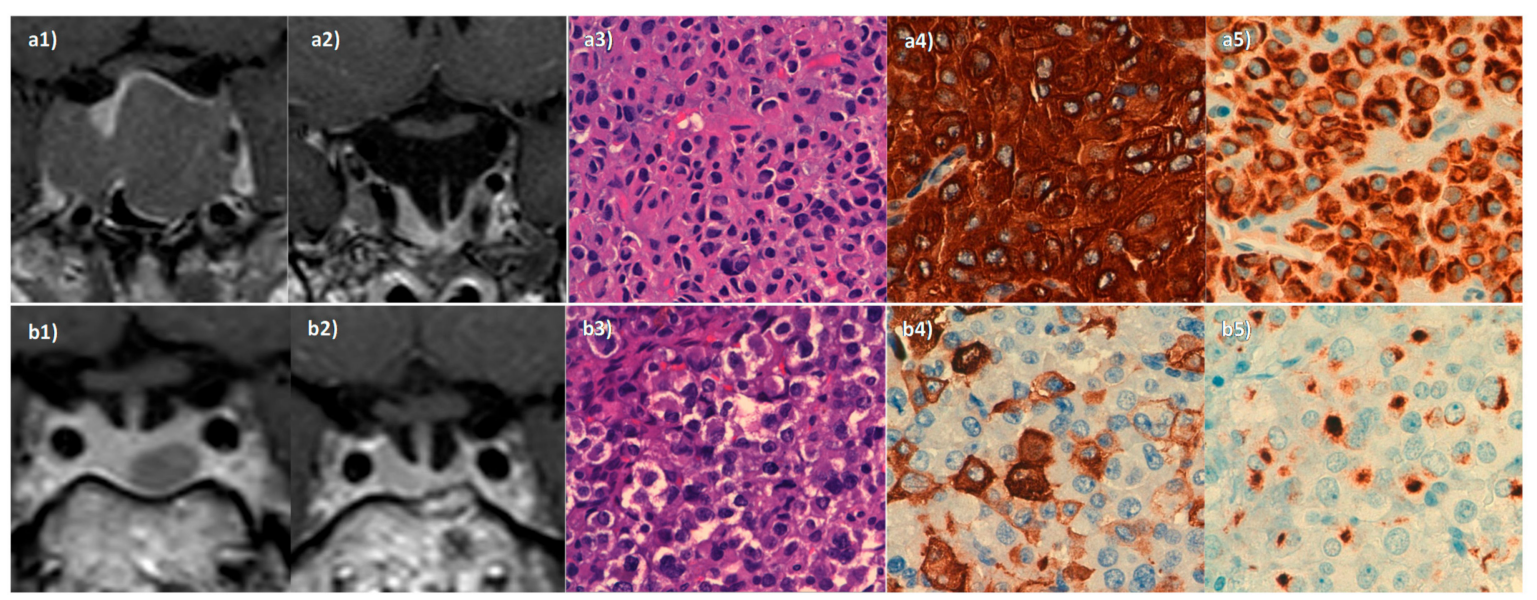

Figure 2. Histological images of pituitary tumours with different tumours consistencies. Case 1. Invasive pituitary adenomas (Knosp grade 4) of very hard consistency in the preoperative (a1) and (a2) small remnant in right cavernous sinus in the postoperative (coronal sections). The specimen was a densely granulated somatotroph tumour. Hematoxylin-eosin (a3) showed an acidophilic tumour, that stained strongly for GH (a4). Cytokeratin CAM5.2 (a5) staining was diffuse with a reinforce perinuclear pattern. Case 2. Knosp grade O pituitary adenomas of soft consistency in the preoperative (b1) and postoperative with complete tumoral resection (b2) (coronal sections). The lesion was a sparsely granulated somatotroph tumour. Hematoxylin-eosin (b3) revealed a chromophobic tumour with focal GH staining (b4). Cytokeratin CAM5.2 (b5) showed a dot-like perinuclear pattern corresponding to fibrous bodies. 


\section{Discussion}

In this study, we found that preoperative long-acting SSA treatment with monthly doses equal or higher than $90 \mathrm{mg}$ of lanreotide or $30 \mathrm{mg}$ of octreotide for at least 3 months was associated with a global higher surgical remission rate according to the 2010 criteria. However, we did not observe any benefits of presurgical SSAs treatment in terms of surgical and endocrine complications.

In our study, no differences in surgical remission according 2010 were found between pre-treated and untreated patients when all doses of SSAs were considered. Based on the 2000 criteria, similar results were reported in several previous studies $[19,24]$. However, to the best of our knowledge, no previous studies have observed similar result as ours based on the 2010 criteria. On the other hand, an improvement in surgical outcomes with presurgical SSAs therapy has been described in a previous study based on this criterium [25]. The different study populations could explain these differences, as not in all studies, important variables such as age, baseline GH and Knosp grade are comparable between pre-treated and untreated group, or even patients operated by different neurosurgeons were included in the analysis [18]. Different surgical remission criteria and variables formulations and doses of SSAs have been used in each study.

When the different tumour volumes were compared, we could not demonstrate a significant difference between pre-treated and untreated cases for microadenomas, macroadenomas and invasive adenomas in terms of surgical cure when conventional doses were used. This is in line with the reported by other authors [19,24]. Nevertheless, a recent meta-analysis [26] found that patients with macroadenomas in the SSAs pre-treatment groups have had a more significantly cure rate than those untreated $(R R=2.27,95 \% \mathrm{CI}$ $=1.34-3.84)$, although no differences were found in long-term surgical remission $(\mathrm{RR}=$ $1.03,95 \% \mathrm{CI}=0.86-1.24)$. This observation was also reported in other previous individual studies [14], and even in two randomized clinical trials [14,27]. Therefore, in general, most studies, and different meta-analysis $[17,28,29]$, supported that those patients with macroadenomas are more likely to benefit in terms of improved surgical remission.

No differences were found between both formulations of long acting SSA in terms of surgical outcomes in our study. Similar results were reported by several previous studies [17,30], including one randomized clinical trial [31]. On the other hand, in a recent meta-analysis [6], the efficacy of octreotide LAR was greater than lanreotide. However, Zhang et al. [31] in their meta-analysis proved benefits from lanreotide (RR 2.27, $95 \% \mathrm{CI}=1.34-3.84)$, but not from octreotide ( $\mathrm{RR} 1.51,95 \% \mathrm{CI}=0.82-2.75)$ in short term postoperative biochemical remission

We observed a clear benefit of high doses of SSA based on the 2010 criteria, as pretreated patients with high doses achieved surgical remission near to five-times more commonly than untreated or treated with lower doses. This finding is supported by the PRIMARYS study [7], which showed that primary treatment with lanreotide Autogel at the highest allowed doses provides clinically significant reductions $(>20 \%)$ in tumour volume in $62.9 \%$ of patients at 1 year; and by the Caron clinical trial [32], which found that GH hypersecretion was reduced to $\leq 2.5 \mu \mathrm{g} / \mathrm{L}$ in $68 \%$ of patients with titrated dose lanreotide Autogel compared with $56 \%$ with fixed-dose $(p<0.005)$. These results are in accordance with those described by previous studies that have found there are a correlation between the serum concentrations of SSAs and their long-term efficacy against GH hypersecretion [33]. Higher SSA doses may be associated with tumour shrinkage and softening of their consistency, facilitating surgical removal. Moreover, presurgical GH levels and tumour size are well-known predictive factors of surgical remission [3]. The benefit of high doses of SSAs seemed to be limited to the group of macroadenomas as we did not find any differences were in the microadenoma group according to the dose of SSA, but the limited sample size in our study may have influenced these results.

We also did not detect any difference in the occurrence or severity of perioperative complications, in the hospitalization time, or in the risk of pituitary insufficiency. This in accordance with the reported by several previous studies where no differences were found, 
either. However, Colao et al. [34] reported a significantly shorter period of postoperative hospitalization in patients with acromegaly who underwent treatment with octreotide before surgery ( $5.6 \pm 0.5$ days) compared with those who did not ( $8.6 \pm 0.7$ days), suggesting that it could be related to a lower frequency of cardiac arrhythmia, respiratory impairment and respiratory infections in the treated group.

The study has some limitations. First, the retrospective nature of the study, and the number of patients was relatively small, so the possibility of a type 2 error should be considered. Nevertheless, all patients with missing data in the main variables were excluded of the study, and most patients $(n=34)$ were prospectively included in the study. It is a two-center study performed mostly in a Pituitary Center of Excellence (Ramón y Cajal Hospital) [5], so surgical outcomes cannot be extrapolated to other centers with a low-pituitary tumour surgery volume and operated by other neurosurgeons with less experience. Moreover, we had not analyzed other aspects that can be improved with presurgical SSA such as hemodynamic parameters and quality of life, and only patients with first long-acting SSA were included in the study, so it could be expected that, in patients not adequately controlled on first generation-SSA pasireotide would be more adequate [35] and a benefit of presurgical treatment would be achieved.

\section{Conclusions}

The dose of SSAs is a key factor during pre-surgical treatment since the beneficial effects in surgical remission were observed with doses equal or higher than $90 \mathrm{mg} / \mathrm{month}$ of lanreotide and $30 \mathrm{mg} / \mathrm{month}$ of octreotide, but not with lower doses. Pre-treatment with SSAs has no effect on the risk of surgical and endocrine complications.

Author Contributions: M.A.-C., E.P.-C., H.P., I.R.-C., A.A.C., S.G.D. and V.R.B. have made substantial contribution to the conception and the design of the work. All authors have read and agreed to the published version of the manuscript.

Funding: This research received no external funding.

Institutional Review Board Statement: All procedures performed in the participants of the study were in accordance with the ethical standards of the institutional research committee and with the 1964 Helsinki declaration and its later amendments or comparable ethical standards. The study has been approved by the Ethical Committee of the Ramón y Cajal University Hospital and Hospital HM Madrid (approval date: 4 October 2019, code: ACTA 372).

Informed Consent Statement: Due to the retrospective nature of the study, the Ethical Committee has approved the need of informed consent only in those patients who continued in follow-up in our center.

Data Availability Statement: Not applicable.

Conflicts of Interest: The authors declare no conflict of interest.

\section{References}

1. Bolfi, F.; Neves, A.F.; Boguszewski, C.; Nunes-Nogueira, V.S. Mortality in acromegaly decreased in the last decade: A systematic review and meta-analysis. Eur. J. Endocrinol. 2019, 181, L5-L6. [CrossRef] [PubMed]

2. Katznelson, L.; Laws, E.R.; Melmed, S.; Molitch, M.E.; Murad, M.H.; Utz, A.; Wass, J.A.H. Acromegaly: An Endocrine Society Clinical Practice Guideline. J. Clin. Endocrinol. Metab. 2014, 99, 3933-3951. [CrossRef] [PubMed]

3. Araujo-Castro, M.; Pascual-Corrales, E.; Martínez-Vaello, V.; Saiz, G.B.; De Silva, J.Q.; Cancela, A.A.; Cano, A.M.G.; Berrocal, V.R. Predictive model of surgical remission in acromegaly: Age, presurgical GH levels and Knosp grade as the best predictors of surgical remission. J. Endocrinol. Investig. 2021, 44, 183-193. [CrossRef] [PubMed]

4. Kim, E.H.; Oh, M.C.; Lee, E.J.; Kim, S.H. Predicting Long-term Remission by Measuring Immediate Postoperative Growth Hormone Levels and Oral Glucose Tolerance Test in Acromegaly. Neurosurgery 2012, 70, 1106-1113. [CrossRef] [PubMed]

5. Araujo-Castro, M.; Pascual-Corrales, E.; Millan, J.S.M.S.; Rebolleda, G.; Pian, H.; Ruz-Caracuel, I.; Granados, G.D.L.S.; Urzaiz, L.L.; Escobar-Morreale, H.; Berrocal, V.R. Postoperative management of patients with pituitary tumors submitted to pituitary surgery. Experience of a Spanish Pituitary Tumor Center of Excellence. Endocrine 2020, 69, 5-17. [CrossRef]

6. Freda, P.; Katznelson, L.; Van Der Lely, A.-J.; Reyes, C.M.; Zhao, S.; Rabinowitz, D. Long-Acting Somatostatin Analog Therapy of Acromegaly: A Meta-Analysis. J. Clin. Endocrinol. Metab. 2005, 90, 4465-4473. [CrossRef] 
7. Caron, P.J.; Bevan, J.S.; Petersenn, S.; Flanagan, D.; Tabarin, A.; Prévost, G.; Maisonobe, P.; Clermont, A.; on behalf of the PRIMARYS Investigators. Tumor Shrinkage with Lanreotide Autogel $120 \mathrm{mg}$ as Primary Therapy in Acromegaly: Results of a Prospective Multicenter Clinical Trial. J. Clin. Endocrinol. Metab. 2014, 99, 1282-1290. [CrossRef] [PubMed]

8. Colao, A.; Auriemma, R.S.; Pivonello, R. The effects of somatostatin analogue therapy on pituitary tumor volume in patients with acromegaly. Pituitary 2016, 19, 210-221. [CrossRef]

9. Ben-Shlomo, A.; Melmed, S. The Role of Pharmacotherapy in Perioperative Management of Patients with Acromegaly. J. Clin. Endocrinol. Metab. 2003, 88, 963-968. [CrossRef]

10. Losa, M.; Bollerslev, J. Pros and cons in endocrine practice: Pre-surgical treatment with somatostatin analogues in acromegaly. Endocrine 2016, 52, 451-457. [CrossRef]

11. Fleseriu, M.; Hoffman, A.R.; Katznelson, L. American Association of Clinical Endocrinologists and American College of Endocrinology Disease State Clinical Review: Management of Acromegaly Patients: What is the Role of Pre-Operative Medical Therapy? Endocr. Pr. 2015, 21, 668-673. [CrossRef] [PubMed]

12. Stevenaert, A.; Beckers, A. Presurgical Octreotide: Treatment in acromegaly. Metabolism 1996, 45, 72-74. [CrossRef]

13. Ferone, D.; Gatto, F.; Minuto, F. Pre-surgical treatment with somatostatin analogues in patients with acromegaly: The case for. $J$. Endocrinol. Investig. 2012, 35, 613-615. [CrossRef] [PubMed]

14. Carlsen, S.M.; Lund-Johansen, M.; Schreiner, T.; Aanderud, S.; Johannesen, Ø.; Svartberg, J.; Cooper, J.G.; Hald, J.K.; Fougner, S.L.; Bollerslev, J. Preoperative Octreotide Treatment in Newly Diagnosed Acromegalic Patients with Macroadenomas Increases Cure Short-Term Postoperative Rates: A Prospective, Randomized Trial. J. Clin. Endocrinol. Metab. 2008, 93, 2984-2990. [CrossRef]

15. Lv, L.; Hu, Y.; Zhou, P.; Zhang, S.; Yin, S.; Zhang, N.; Jiang, S. Presurgical treatment with somatostatin analogues in growth hormone-secreting pituitary adenomas: A long-term single-center experience. Clin. Neurol. Neurosurg. 2018, 167, 24-30. [CrossRef]

16. Maiza, J.C.; Vezzosi, D.; Matta, M.; Donadille, F.; Loubes-Lacroix, F.; Cournot, M.; Bennet, A.; Caron, P. Long-term (up to 18 years) effects on GH/IGF-1 hypersecretion and tumour size of primary somatostatin analogue (SSTa) therapy in patients with GH-secreting pituitary adenoma responsive to SSTa. Clin. Endocrinol. 2007, 67, 282-289. [CrossRef]

17. Zhang, L.; Wu, X.; Yan, Y.; Qian, J.; Lu, Y.; Luo, C. Preoperative somatostatin analogs treatment in acromegalic patients with macroadenomas. A meta-analysis. Brain Dev. 2015, 37, 181-190. [CrossRef]

18. Quabbe, H.-J. Presurgical octreotide treatment in acromegaly: No improvement of final growth hormone (GH) concentration and pituitary function. A long-term case-control study. Acta Neurochir. 2005, 147, 485-493. [CrossRef]

19. Losa, M.; Mortini, P.; Urbaz, L.; Ribotto, P.; Castrignanò, T.; Giovanelli, M. Presurgical treatment with somatostatin analogs in patients with acromegaly: Effects on the remission and complication rates. J. Neurosurg. 2006, 104, 899-906. [CrossRef]

20. Melmed, S.; Sternberg, R.; Cook, D.; Klibanski, A.; Chanson, P.; Bonert, V.; Vance, M.L.; Rhew, D.; Kleinberg, D.; Barkan, A. A Critical Analysis of Pituitary Tumor Shrinkage during Primary Medical Therapy in Acromegaly. J. Clin. Endocrinol. Metab. 2005, 90, 4405-4410. [CrossRef]

21. Giustina, A.; Chanson, P.; Bronstein, M.D.; Klibanski, A.; Lamberts, S.; Casanueva, F.F.; Trainer, P.; Ghigo, E.; Ho, K.; Melmed, S. A Consensus on Criteria for Cure of Acromegaly. J. Clin. Endocrinol. Metab. 2010, 95, 3141-3148. [CrossRef] [PubMed]

22. Araujo-Castro, M.; Pascual-Corrales, E.; Cancela, A.A.; Duque, S.G.; Urzaiz, L.L.; Berrocal, V.R. Status and clinical and radiological predictive factors of presurgical anterior pituitary function in pituitary adenomas. Study of 232 patients. Endocrine 2020, 70, 584-592. [CrossRef] [PubMed]

23. Araujo-Castro, M.; Pian, H.; Ruz-Caracuel, I.; Cancela, A.A.; Pascual-Corrales, E.; Berrocal, V.R. Presurgical somatostatin receptor ligand treatment does not affect tumor consistency in GH-secreting pituitary macroadenomas. Endocr. Connect. 2021, 10, 102-109. [CrossRef]

24. Biermasz, N.R.; Van Dulken, H.; Roelfsema, F. Direct Postoperative and Follow-Up Results of Transsphenoidal Surgery in 19 Acromegalic Patients Pretreated with Octreotide Compared to Those in Untreated Matched Controls. J. Clin. Endocrinol. Metab. 1999, 84, 3551-3555. [CrossRef]

25. Albarel, F.; Castinetti, F.; Morange, I.; Guibert, N.; Graillon, T.; Dufour, H.; Brue, T. Pre-surgical medical treatment, a major prognostic factor for long-term remission in acromegaly. Pituitary 2018, 21, 615-623. [CrossRef] [PubMed]

26. Yang, C.; Li, G.; Jiang, S.; Bao, X.; Wang, R. Preoperative Somatostatin Analogues in Patients with Newly-diagnosed Acromegaly: A Systematic Review and Meta-analysis of Comparative Studies. Sci. Rep. 2019, 9, 1-9. [CrossRef]

27. Mao, Z.-G.; Zhu, Y.-H.; Tang, H.-L.; Wang, D.-Y.; Zhou, J.; He, D.-S.; Lan, H.; Luo, B.-N.; Wang, H.-J. Preoperative lanreotide treatment in acromegalic patients with macroadenomas increases short-term postoperative cure rates: A prospective, randomised trial. Eur. J. Endocrinol. 2010, 162, 661-666. [CrossRef]

28. Pita-Gutiérrez, F.; Pértega-Díaz, S.; Pita-Fernandez, S.; Pena, L.; Lugo, G.; Sangiao-Alvarellos, S.; Cordido, F. Place of Preoperative Treatment of Acromegaly with Somatostatin Analog on Surgical Outcome: A Systematic Review and Meta-Analysis. PLoS ONE 2013, 8, e61523. [CrossRef]

29. Nunes, V.S.; Correa, J.M.S.; Puga, M.E.S.; Silva, E.M.K.; Boguszewski, C. Preoperative somatostatin analogues versus direct transsphenoidal surgery for newly-diagnosed acromegaly patients: A systematic review and meta-analysis using the GRADE system. Pituitary 2014, 18, 500-508. [CrossRef] 
30. Alexopoulou, O.; Abrams, P.; Verhelst, J.; Poppe, K.; Velkeniers, B.; Abs, R.; Maiter, D. Efficacy and tolerability of lanreotide Autogel therapy in acromegalic patients previously treated with octreotide LAR. Eur. J. Endocrinol. 2004, 151, 317-324. [CrossRef]

31. Andries, M.; Glintborg, D.; Kvistborg, A.; Hagen, C.; Andersen, M. A 12-month randomized crossover study on the effects of Lanreotide Autogel and Octreotide long-acting repeatable on GH and IGF-1 in patients with acromegaly. Clin. Endocrinol. 2007, 68, 473-480. [CrossRef] [PubMed]

32. Caron, P.; Bex, M.; Cullen, D.R.; Feldt-Rasmussen, U.; Alfonso, A.M.P.; Pynka, S.; Rácz, K.; Schopohl, J.; Tabarin, A.; Välimäki, M.J.; et al. One-year follow-up of patients with acromegaly treated with fixed or titrated doses of lanreotide AutogelR. Clin. Endocrinol. 2004, 60, 734-740. [CrossRef] [PubMed]

33. Sassolas, G.; Harris, A.G.; James-Deidier, A. Long Term Effect of Incremental Doses of the Somatostatin Analog SMS 201-995 in 58 Acromegalic Patients*. J. Clin. Endocrinol. Metab. 1990, 71, 391-397. [CrossRef] [PubMed]

34. Colao, A.; Ferone, D.; Cappabianca, P.; Caro, M.L.D.B.D.; Marzullo, P.; Monticelli, A.; Alfieri, A.; Merola, B.; Cali, A.; De Divitiis, E.; et al. Effect of Octreotide Pretreatment on Surgical Outcome in Acromegaly. J. Clin. Endocrinol. Metab. 1997, 82, $3308-3314$. [CrossRef] [PubMed]

35. Gadelha, M.R.; Bronstein, M.D.; Brue, T.; Coculescu, M.; Fleseriu, M.; Guitelman, M.; Pronin, V.; Raverot, G.; Shimon, I.; Lievre, K.K.; et al. Pasireotide versus continued treatment with octreotide or lanreotide in patients with inadequately controlled acromegaly (PAOLA): A randomised, phase 3 trial. Lancet Diabetes Endocrinol. 2014, 2, 875-884. [CrossRef] 